\title{
WHAT DO WE WANT AND WHAT DO WE GET FROM THE COACH? PREFERRED AND PERCEIVED LEADERSHIP IN MALE AND FEMALE TEAM SPORTS
}

original paper

( ) University School of Physical Education in Wroclaw

DOI: https://doi.org/10.5114/hm.2019.79734

\section{ZUZANNA MARIA WAŁACH-BIŚTA}

\begin{abstract}
Purpose. The purpose of the study was to investigate any similarities or differences between the genders in the scope of preferred coaching behaviours. Moreover, it was an attempt at establishing whether there are discrepancies between the respondents' expectations and their evaluation of the actual perceived behaviour of the coaches towards them. It was also considered whether the type of the played sport would differentiate the respondents depending on their expectations.

Methods. The study consisted of two stages. The athletes' preferences concerning coaching behaviours were studied with the 'athletes' preferences' version of the Leadership Scale for Sports. The perceived coaching behaviour was evaluated by the athletes at the end of the season with the 'coach's behaviour as perceived by the athletes' version of the scale.

Results. Significant differences between women and men were observed when it comes to their preferences concerning coaching behaviours. Moreover, the analysis for dependent samples demonstrated that the athletes received from the coaches fewer coaching-related instructions, less feedback, and fewer democratic behaviours than they would have expected.

Conclusions. The results indicate that women and men differ in their preferences concerning coaching behaviours. These differences, however, are not big. The played sport may also have a significant influence on the expectations regarding the coach's behaviour; this observation is, however, limited to women. Regardless of the athletes' gender, coaches provided them with less behaviours than the athletes would have expected. This implies that coaches adjust their behaviour to the athletes' preferences and the situational requirements in an inadequate manner.
\end{abstract}

Key words: leadership, preferred coaching behaviours, perceived coaching behaviours, team sports

\section{Introduction}

It is commonly believed that each success, but also each failure of an athlete can be attributed to the coach. It is the coach's behaviour that is considered the key component determining the performance of the athlete or of the whole team. This is because one of the most important tasks of a coach in sports is to help the athlete achieve greater efficiency and develop their sports potential to the fullest extent. Martens [1] stressed that being a coach was a very difficult profession that required extraordinary skills. It is the coach who is responsible for the athlete's motor, technical, tactical, as well as psychological preparation. The coach exercises enormous influence on the athletes, shaping their level of motivation and impacting them pedagogically. Through his or her behaviour, the coach conditions not only the athletes' effectiveness, but also their mental well-being [2]. Because of that, the leadership function is intrinsically linked to the role of the coach [3]. Owing to the tasks and responsibilities entrusted to the coach, they are recognized as the formal leader. For that reason, most psychological concepts that apply to the world of sports identify the leader with the coach [e.g. 4, 5].

The Multidimensional Model of Sport Leadership provides an important theoretical background for studying the issues pertaining to leadership, and thus also coaching behaviour in sports. The basic assumption of that model is treating leadership as a complex process, determined by many factors. The characteristics of the athletes, the coach, and the situation influence the coach's behaviour. As a result of that, the coach's behaviour plays an important role in shaping the athletes' satisfaction level. Moreover, it impacts on the individual and team level of efficacy and effectiveness [6]. Additionally, the central hypothesis of the model is the statement that the athletes' effectiveness

Correspondence address: Zuzanna Wałach-Biśta, e-mail: zwalach@gmail.com

Received: September 21, 2018

Accepted for publication: November 17, 2018

Citation: Wałach-Biśta ZM. What do we want and what do we get from the coach? Preferred and perceived leadership in male and female team sports. Hum Mov. 2019;20(3):38-47; doi: https://doi.org/10.5114/hm.2019.79734. 
and level of satisfaction depend on the degree to which the current behaviour of the coach is consistent with the coach's behaviour model preferred by the athletes and on the requirements and limitations imposed on the coach. This relationship is commonly believed to be positive - i.e. the more the coach's behaviour is consistent with the athletes' preferences and the situational requirements, the higher the expected level of the athletes' effectiveness and satisfaction [7]. The Multidimensional Model of Sport Leadership assumes that the behaviour exhibited by the coach is dependent both on the expectations of the athletes concerning the number of instructions, the support, and feedback provided by the coach and on the requirements and limitations pertaining to a given situation, that is, the required behaviour [8]. In his model, Chelladurai [4] stresses the importance of the degree of conformity between three behaviours of the leader: the current, preferred, and required behaviour. This conformity impacts on the athletes' effectiveness and performance as well as their contentment and satisfaction with the sport. Therefore, it is crucial for coaches to be aware of which behaviours and which intensity of these behaviours are expected from them by the athletes. Such knowledge should help them adjust their behaviour to the current situation and to the athletes' preferences, so that, in consequence, it would enable them to positively influence the athletes they are working with.

The coach's behaviour preferred by their charges relates mainly to the preferences concerning the instructions and tips given during the training process, to the supplied social support, and to the type and frequency of the supplied feedback [9]. According to Chelladurai and Carron [8], it results from both situational factors and individual characteristics of the athletes themselves. However, the individual preferences, personality traits, needs, cognitive abilities, and skills of the athletes have direct influence on their preferred coaching behaviour.

According to the Multidimensional Model of Sport Leadership, one of such key factors differentiating the preferences concerning leadership is the sex of the athletes. The importance of the athletes' sex in the context of expectations concerning coaching behaviour has been studied extensively in both team and individual sports [10-16]. Current findings indicate that the chief area of significant difference between women and men is their expectations concerning the leadership style exhibited by the coach. As compared with women, men definitely prefer for their coach to exhibit more autocratic behaviours [10, 12-15]. A coach with such a leadership style is characterized by a greater orientation on tasks and winning, as well as by a rigor- ous work organization. Women, in turn, attach more importance (as compared with men) to their opportunities to participate in making decisions. Because of that, they prefer for the coach to exhibit more democratic behaviours towards them [11, 12, 16, 17]. Such a coach focuses mainly on the athletes and he or she is more often someone focused on cooperation. Women tend to lean towards coaches who will not only accept their participation, but also create opportunities to reach joint sports-related decisions [17].

Moreover, men expected social support from their coach more often than women [10,13]. However, Riemer and Toon [15] demonstrated in their research that the expectations of women concerning coaching behaviours related to the supplied social support changed depending on the sex of the coach. Women expected more social support from a male coach than from a female coach.

The existing research does not provide a clear answer with regard to the differences in preferences concerning the coach's behaviour in the remaining dimensions of coaching behaviours. The research conducted in the 1970s by Chelladurai and Saleh [12] showed that men were the ones who expected their coaches to provide them with more instructions and tips related to training. However, a newer study by Beam et al. [10] demonstrated a reverse relationship, indicating that women expected more instructions and technical tips than men. The results of two other studies suggest that to women, positive feedback from their coach means a lot and that it is a behaviour that they expect more often than men $[15,16]$. It is worth noting, though, that men and women differ from each other in their expectations concerning the coach's behaviour only slightly. Very often the results demonstrate more similarities between the sexes than expected differences [16].

In summary, the degree of similarity or divergence between the sexes in the scope of coaching behaviour preferences remains unclear - especially among Polish athletes - and requires further research. It also seems that it would be interesting to verify whether coaches correctly read the expectations of their athletes concerning their behaviours and whether they adjust their behaviour to the expectations of the group that they work with. Therefore, the purpose of this study was to investigate any similarities or differences between the sexes with regard to preferred coaching behaviours. Moreover, it was an attempt at establishing whether there are discrepancies between the respondents' expectations and their evaluation of the actual perceived behaviour of the coaches towards them. It was also considered whether the type of the played sport (basket- 
ball vs. volleyball) would differentiate the respondents depending on their expectations.

\section{Material and methods}

\section{Research procedure}

The study encompassed female and male teams of two sports: basketball and volleyball, participating in league matches in the area of the Silesian, Lesser Poland, and Greater Poland provinces. The research consisted of two stages and was conducted during two regular league seasons: in the 2014/2015 and 2015/2016 season.

During the first stage, which took place at least two weeks before the commencement of league matches in the regular season, the respondents filled in a demographics sheet and the 'athletes' preferences' version of the Leadership Scale for Sports [18] in order to determine their expectations concerning the coach's behaviour. After the conclusion of the regular season, i.e. in the second stage of the study, the athletes filled in the demographics sheet and the 'coach's behaviour as perceived by the athletes' version of the Leadership Scale for Sports [18] in order to determine their perceptions of the coaching behaviour towards them during the whole regular season.

For reasons beyond the control of the researchers, in the second stage of the research it was not possible to study all the teams that participated in the first stage.

After obtaining the initial consent of the club authorities and the team coaches, the author would make suitable appointments with the coaches (before or after the training). During the meetings, the athletes were informed of the research aim, the confidentiality of storing and processing the results, and the voluntary character of participation in the study. Subsequently, the athletes would fill in the prepared questionnaires and return them directly to the author.

\section{Participants}

\section{Participants in the first stage}

In all, the first study encompassed 352 athletes, including 161 women and 191 men. The mean age of the respondents was a little over 22 years $(M=22.67$; $S D$ $=4.92 ; \min =16 ; \max =41)$. At average, the participants had been practicing the selected sport for over 10 years $(M=10.32 ; S D=4.60 ; \min =3 ; \max =29)$. The respondents belonged to 28 different sports teams: basketball (12 teams) and volleyball (16 teams). The majority of the studied teams $(n=20)$ participated in league matches at the level of the $2^{\text {nd }}$ league. All the coaches of the studied teams were male.

\section{Participants in the second stage}

In all, the second research stage encompassed 204 athletes, including 106 women and 98 men; 88\% of the studied athletes were persons who had also participated in the first stage of the study $(n=180)$. The age of the respondents and the number of years practicing a given sport was not significantly different from the characteristics of the team members examined in the first stage of the study. The respondents were members of 18 sports teams. Again, the majority of the studied teams $(n=12)$ participated in league matches at the level of the $2^{\text {nd }}$ league. Over $55 \%$ of the researched teams were teams playing volleyball, and the remaining part consisted of basketball teams.

\section{Measures}

\section{Demographics sheet}

The proprietary survey contained basic questions concerning sociodemographic characteristics and questions pertaining to the functioning of the respondents in sports. The questions in the demographics sheet were aimed at determining the played sport, the number of years playing the given sport, and the length of time in the team. Moreover, the questions concerning the first letter of the father's and mother's name and place of birth allowed to ascribe a unique code to each person, thanks to which in the next study it was possible to connect the measurement of a person with the previous results while preserving their anonymity.

\section{Leadership Scale for Sports: Polish version}

The applied scale is a Polish adaptation [18] of the Leadership Scale for Sports [3]. It surveys leadership as understood by the Multidimensional Model of Sport Leadership. The questionnaire examines five main characteristic behaviours of the coach as a leader. It allows to determine the degree to which the coach provides positive feedback and social support and trains and instructs their charges, as well as his or her democratic and autocratic behaviour. The scale consists of 40 items, to which the respondent reacts on a 5-point scale (never, seldom, occasionally, often, always). There are two versions of the Polish adaptation, which can be used in the measurement of (a) coaching behaviours 
preferred by the athletes, (b) the opinion of the athletes concerning the current behaviour of the coach. The Polish version is characterized by a high validity and satisfactory reliability. The Cronbach's alpha of the aforementioned subscales varied from 0.61 to 0.84 depending on the scale version [18]. The obtained results of subscale reliability analysis were as follows: 0.81 (training and instruction), 0.81 (feedback), 0.76 (democratic behaviour), 0.66 (autocratic behaviour), and 0.65 (social support) for the 'athletes' preferences' version, whereas $0.92,0.86,0.85,0.69$, and 0.72 , respectively, for the 'coach's behaviour as perceived by the athletes' version.

\section{Data analysis}

To compare the preferences of male vs. female athletes concerning coaching behaviour, the preferences of basketball vs. volleyball players, and the athletes' preferences vs. the perceived behaviour of the coach, descriptive statistics was used to obtain the average and standard deviation of the data. To verify the data distribution normality, the Shapiro-Wilk test was applied, pointing out that the data did not have a nonparametric distribution. This is why the study employed the Mann-Whitney U test, Wilcoxon signed-ranks test for dependent samples, and $\rho$-Spearman's nonparametric correlations. For this analysis, to calculate the size of the effects, the Glass rank-biserial coefficient of correlation and the matched pairs rank biserial correlation coefficient were used [19].

For all subjects, preference and perception scores were calculated by summing the scores of all the items in a particular coaching dimension and dividing the obtained value by the number of items in that dimension [3].

For all analyses, the significance level of $\alpha=0.05$ was assumed and the PS IMAGO software was used.

\section{Ethical approval}

The research related to human use has complied with all the relevant national regulations and institutional policies, has followed the tenets of the Declaration of Helsinki, and has been approved by the authors' institutional review board or an equivalent committee.

\section{Informed consent}

Informed consent has been obtained from all individuals included in this study.

\section{Results}

Differences and similarities in preferences concerning coaching behaviours

and the perceived behaviour of the coach depending on the athletes' sex

Table 1 presents the results of the comparative analyses between women and men regarding their preferences concerning coaching behaviours and the perceived behaviour of the coach. The obtained results indicate that both women and men expect from their coaches a similar frequency of specific behaviours, with only marginal variation in their preference scores for each of the behaviours. As compared with men, women expect only slightly more training and instructing behaviours (female: $M=4.31 \pm 0.48$; male: $M=4.23 \pm 0.46$ ), positive feedback (female: $M=$ $3.92 \pm 0.67$; male: $M=3.76 \pm 0.59$ ), and democratic behaviour (female: $M=3.16 \pm 0.69$; male: $M=2.99 \pm$ 0.58 ). As compared with women, men prefer a little more autocratic behaviours of their coaches (female: $M=2.31 \pm 0.56$; male: $M=2.56 \pm 0.60$ ). However, the effect size analysis also shows that the obtained differences in the preferences concerning coaching behaviours can be deemed small.

Further analyses demonstrated that women and men did not differ significantly when it came to the perceived behaviour of the coach towards them. The data only indicate that women receive from their coaches a little more social support that men. These differences can be deemed moderate (female: $M=2.79 \pm 0.65$; male: $M=2.46 \pm 0.59$ ).

Age, years of training, length of time

in the team and athletes' preferences

Table 2 presents the results of the correlation analyses conducted for women and men separately. The obtained data indicate that the age of the athletes, the duration of training a given sport, and the time of being a part of a given team are not significantly correlated with preferences concerning coaching behaviours. Only with age, and consequently with years of training, the expectations concerning the amount of social support received from the coach drop among men $(\rho=$ $-0.21 ; p<0.01)$.

Type of sport and athletes' preferences and coach's behaviour as perceived by the athletes

Table 3 presents the results of comparative analyses of women playing volleyball and women playing bas- 


\section{HUMAN MOVEMENT}

Z. Wałach-Biśta, Athletes’ preferences, coaching behaviour

Table 1. Differences between women and men with regard to preferences concerning coaching behaviours and the perceived coach's behaviour

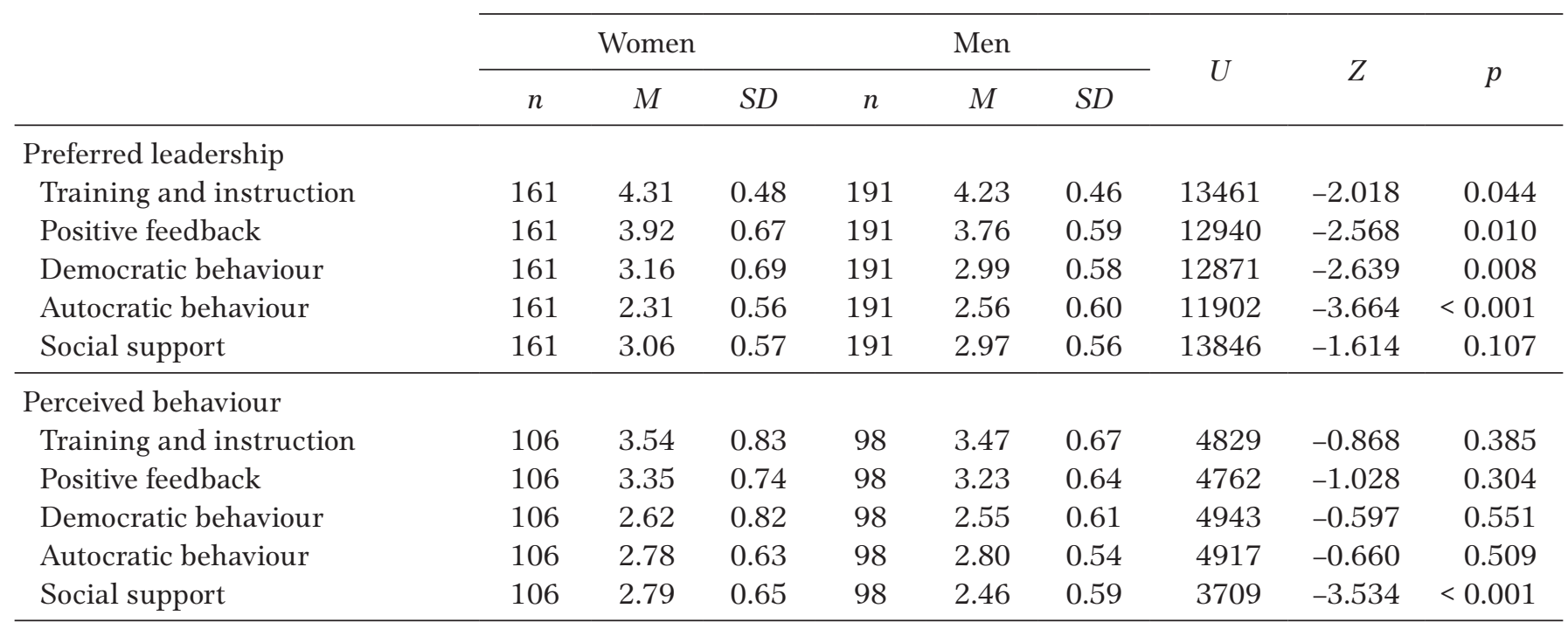

$p$ values for two-tailed test

Table 2. Spearman correlation coefficients for age, years of training, length of time in the team and athletes' preferences

\begin{tabular}{lcccccc} 
& \multicolumn{3}{c}{ Women } & & \multicolumn{2}{c}{ Men } \\
\cline { 2 - 7 } & age & $\begin{array}{c}\text { years } \\
\text { of training }\end{array}$ & $\begin{array}{c}\text { length of time } \\
\text { in the team }\end{array}$ & age & $\begin{array}{c}\text { years } \\
\text { of training }\end{array}$ & $\begin{array}{c}\text { length of time } \\
\text { in the team }\end{array}$ \\
\hline Training and instruction & 0.012 & -0.012 & 0.010 & -0.099 & -0.024 & -0.084 \\
Positive feedback & 0.013 & 0.029 & $0.132^{*}$ & -0.107 & -0.099 & 0.066 \\
Democratic behaviour & 0.038 & 0.078 & 0.038 & -0.078 & -0.101 & -0.099 \\
Autocratic behaviour & -0.086 & -0.071 & -0.059 & -0.029 & -0.077 & $0.124^{*}$ \\
Social support & -0.036 & -0.050 & -0.066 & $-0.211^{* *}$ & $-0.212^{* *}$ & -0.051 \\
\hline
\end{tabular}

${ }^{*} p<0.1,{ }^{*} p<0.01$ for two-tailed test

Table 3. Differences between women playing volleyball and women playing basketball in terms of their preferences concerning coaching behaviours and the perceived coach's behaviour

\begin{tabular}{|c|c|c|c|c|c|c|c|c|}
\hline \multicolumn{3}{|c|}{ Volleyball } & \multicolumn{3}{|c|}{ Basketball } & \multirow{2}{*}{$U$} & \multirow{2}{*}{$Z$} & \multirow{2}{*}{$p$} \\
\hline$n$ & $M$ & $S D$ & $n$ & $M$ & $S D$ & & & \\
\hline
\end{tabular}

\begin{tabular}{|c|c|c|c|c|c|c|c|c|c|}
\hline \multicolumn{10}{|l|}{ Preferred leadership } \\
\hline Training and instruction & 118 & 4.41 & 0.42 & 43 & 4.05 & 0.55 & 1539.5 & -3.83 & $<0.001$ \\
\hline Positive feedback & 118 & 4.02 & 0.67 & 43 & 3.65 & 0.59 & 1644.5 & -3.42 & 0.001 \\
\hline Democratic behaviour & 118 & 3.22 & 0.69 & 43 & 3.00 & 0.68 & 1973.0 & -2.16 & 0.031 \\
\hline Autocratic behaviour & 118 & 2.32 & 0.56 & 43 & 2.26 & 0.55 & 2444.0 & -0.36 & 0.721 \\
\hline Social support & 118 & 3.11 & 0.59 & 43 & 2.93 & 0.51 & 1936.5 & -2.30 & 0.021 \\
\hline \multicolumn{10}{|l|}{ Perceived behaviour } \\
\hline Training and instruction & 81 & 3.57 & 0.89 & 25 & 3.41 & 0.60 & 834.0 & -1.33 & 0.184 \\
\hline Positive feedback & 81 & 3.37 & 0.79 & 25 & 3.29 & 0.55 & 968.5 & -0.33 & 0.743 \\
\hline Democratic behaviour & 81 & 2.57 & 0.86 & 25 & 2.77 & 0.68 & 869.5 & -1.07 & 0.287 \\
\hline Autocratic behaviour & 81 & 2.82 & 0.68 & 25 & 2.66 & 0.39 & 914.5 & -0.73 & 0.464 \\
\hline Social support & 81 & 2.84 & 0.63 & 25 & 2.62 & 0.69 & 851.5 & -1.20 & 0.230 \\
\hline
\end{tabular}

$p$ values for two-tailed test 
Table 4. Differences between men playing volleyball and men playing basketball in terms of their preferences concerning coaching behaviours and the perceived coach's behaviour

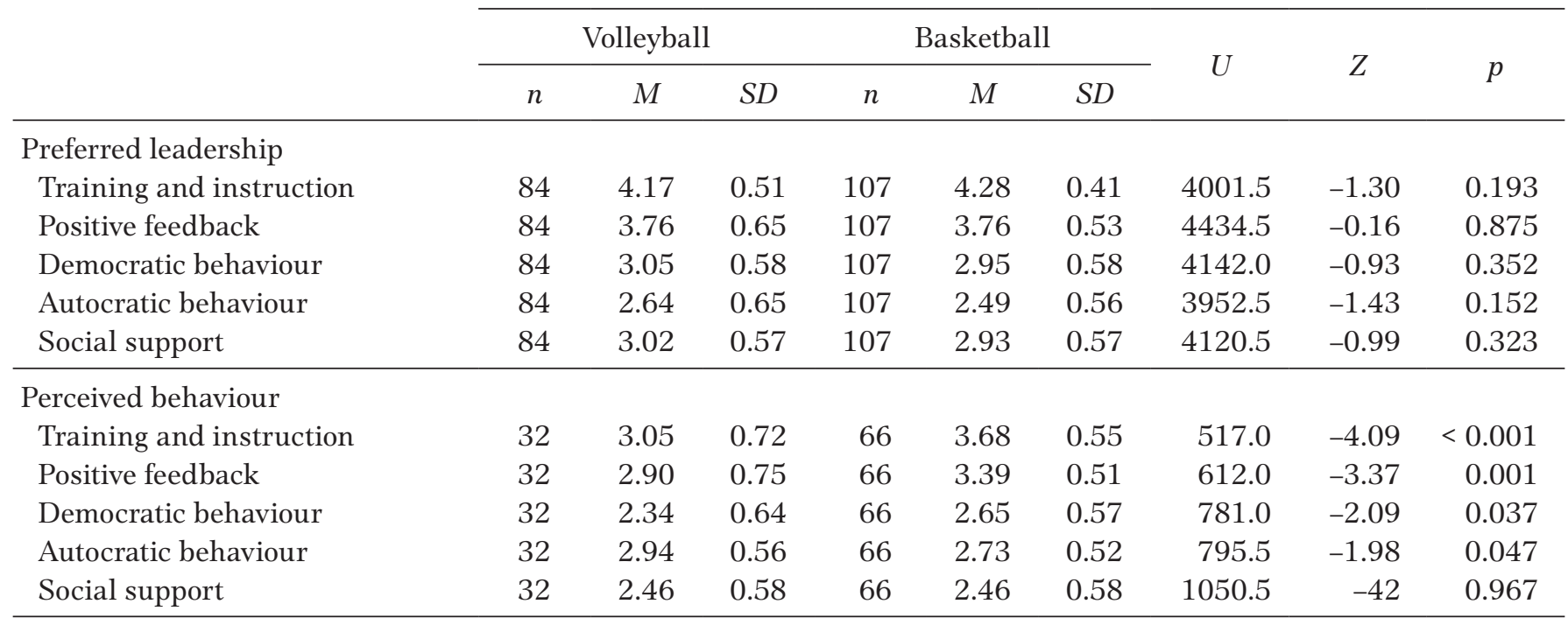

$p$ values for two-tailed test

ketball in the scope of their expectations concerning coaching behaviours. The obtained results indicate that, as compared with basketball players, volleyball players expect from their coaches more instructions related to training (volleyball players: $M=4.41 \pm 0.42$; basketball players: $M=4.05 \pm 0.55$ ), more positive feedback (volleyball players: $M=4.02 \pm 0.67$; basketball players: $M=3.65 \pm 0.59$ ), more democratic behaviours (volleyball players: $M=3.22 \pm 0.69$; basketball players: $M=3.00 \pm 0.68$ ), and more social support (volleyball players: $M=3.11 \pm 0.59$; basketball players: $M=2.93 \pm 0.51$ ). However, the effect size analysis also shows that the obtained differences in preferences concerning coaching behaviours can be deemed small or average.

A comparative analysis between women playing volleyball and women playing basketball with regard to the perceived coach's behaviour did not yield any significant differences between the analysed groups. The obtained results indicate that the studied volleyball and basketball players perceived the behaviour of their coaches in a very similar way (Table 3).

The conducted comparative analyses between men playing volleyball and men playing basketball did not exhibit significant differences in the scope of their preferences concerning coaching behaviours. In turn, the analyses yielded significant differences in terms of the coach's behaviour as perceived by the athletes. The differences concerned training and instruction behaviours, positive feedback, as well as democratic and autocratic behaviours (Table 4).

\section{Expected and received coaching behaviour}

The analysis by means of the Wilcoxon signed-rank test for dependent samples demonstrated that the athletes received from their coaches less instructions related to training (preferences: $M=4.25 \pm 0.45$; perceptions: $M=3.49 \pm 0.75$ ), less positive feedback (preferences: $M=3.88 \pm 0.61$; perceptions: $M=3.29$ \pm 0.68 ), less democratic behaviours (preferences: $M=$ $3.06 \pm 0.63$; perceptions: $M=2.60 \pm 0.73$ ), and less social support (preferences: $M=3.00 \pm 0.57$; perceptions: $M=2.65 \pm 0.63$ ) than they would have expected from them. The athletes also received from their coaches more autocratic behaviours than they would have preferred (preferences: $M=2.43 \pm 0.58$; perceptions: $M=$ $2.80 \pm 0.59$ ). Moreover, the calculated matched pairs rank biserial correlation coefficients indicate that the obtained differences are big and average. Detailed results are included in Table 5 .

Considering gender in the comparative analyses did not yield different results. Separate comparative analyses for men and women also exhibited that both female and male athletes did not receive the amount of the respective coaching behaviours that they would have expected form the coach. Detailed data are presented in Table 6.

Subsequent analyses were an attempt at verifying whether the perception of coaching behaviours by female and male athletes differed depending on the played sport. Table 7 displays the results for men, whereas Table 8 presents the results for women. The obtained results indicate that although women's expectations 


\section{HUMAN MOVEMENT}

Z. Wałach-Biśta, Athletes’ preferences, coaching behaviour

Table 5. Differences between the athletes' preferences concerning coaching behaviours and the coach's behaviour as perceived by the athletes

\begin{tabular}{|c|c|c|c|c|c|c|}
\hline & \multicolumn{2}{|c|}{$\begin{array}{l}\text { Preferred behaviour } \\
\qquad(n=180)\end{array}$} & \multicolumn{2}{|c|}{$\begin{array}{l}\text { Perceived behaviour } \\
\qquad(n=180)\end{array}$} & \multirow[t]{2}{*}{$Z$} & \multirow{2}{*}{$p$} \\
\hline & $M$ & $S D$ & $M$ & $S D$ & & \\
\hline Training and instruction & 4.25 & 0.45 & 3.49 & 0.75 & -9.83 & $<0.001$ \\
\hline Positive feedback & 3.88 & 0.61 & 3.29 & 0.68 & -8.03 & $<0.001$ \\
\hline Democratic behaviour & 3.06 & 0.63 & 2.60 & 0.73 & -6.89 & $<0.001$ \\
\hline Autocratic behaviour & 2.43 & 0.58 & 2.80 & 0.59 & -5.66 & $<0.001$ \\
\hline Social support & 3.00 & 0.57 & 2.65 & 0.63 & -5.97 & $<0.001$ \\
\hline
\end{tabular}

$p$ values for two-tailed test

Table 6. Differences between the athletes' preferences regarding coaching behaviours and the coach's behaviour as perceived by the athletes with regard to the gender of the studied athletes

\begin{tabular}{cccccc}
\hline Preferred behaviour & \multicolumn{2}{c}{ Perceived behaviour } & $Z$ & $p$ \\
\cline { 1 - 2 }$M$ & $S D$ & $M$ & $S D$ & &
\end{tabular}

\begin{tabular}{|c|c|c|c|c|c|c|}
\hline \multicolumn{7}{|l|}{$\operatorname{Men}(n=88)$} \\
\hline Training and instruction & 4.22 & 0.44 & 3.47 & 0.66 & -6.86 & $<0.001$ \\
\hline Positive feedback & 3.81 & 0.55 & 3.22 & 0.63 & -5.73 & $<0.001$ \\
\hline Democratic behaviour & 2.99 & 0.57 & 2.54 & 0.62 & -5.13 & $<0.001$ \\
\hline Autocratic behaviour & 2.52 & 0.59 & 2.81 & 0.54 & -3.59 & $<0.001$ \\
\hline Social support & 2.94 & 0.57 & 2.48 & 0.58 & -4.97 & $<0.001$ \\
\hline \multicolumn{7}{|l|}{ Women $(n=92)$} \\
\hline Training and instruction & 4.30 & 0.46 & 3.51 & 0.83 & -7.05 & $<0.001$ \\
\hline Positive feedback & 3.94 & 0.65 & 3.35 & 0.71 & -5.60 & $<0.001$ \\
\hline Democratic behaviour & 3.12 & 0.68 & 2.64 & 0.83 & -4.70 & $<0.001$ \\
\hline Autocratic behaviour & 2.36 & 0.56 & 2.79 & 0.64 & -4.33 & $<0.001$ \\
\hline Social support & 3.05 & 0.57 & 2.81 & 0.65 & -3.32 & 0.001 \\
\hline
\end{tabular}

$p$ values for two-tailed test

Table 7. Differences between the athletes' preferences concerning coaching behaviours and their perceived coach's behaviours with regard to the played sport in the male group

\begin{tabular}{|c|c|c|c|c|c|}
\hline \multicolumn{2}{|c|}{ Preferred behaviour } & \multicolumn{2}{|c|}{ Perceived behaviour } & \multirow{2}{*}{$Z$} & \multirow{2}{*}{$p$} \\
\hline$M$ & $S D$ & $M$ & $S D$ & & \\
\hline 4.29 & 0.50 & 3.08 & 0.72 & -4.60 & $<0.001$ \\
\hline 4.04 & 0.53 & 2.92 & 0.75 & -4.61 & $<0.001$ \\
\hline 3.04 & 0.58 & 2.36 & 0.65 & -3.46 & 0.001 \\
\hline 2.70 & 0.71 & 2.91 & 0.54 & -1.27 & 0.205 \\
\hline 3.19 & 0.57 & 2.48 & 0.61 & -3.65 & $<0.001$ \\
\hline 4.17 & 0.40 & 3.69 & 0.52 & -4.96 & $<0.001$ \\
\hline 3.68 & 0.53 & 3.39 & 0.49 & -3.30 & 0.001 \\
\hline 2.97 & 0.56 & 2.64 & 0.59 & -4.01 & $<0.001$ \\
\hline 2.42 & 0.50 & 2.76 & 0.54 & -3.77 & $<0.001$ \\
\hline 2.80 & 0.53 & 2.48 & 0.57 & -3.42 & 0.001 \\
\hline
\end{tabular}

$p$ values for two-tailed test 
Table 8. Differences between the athletes' preferences concerning coaching behaviours and their perceived coach's behaviours with regard to the played sport in the female group

\begin{tabular}{|c|c|c|c|c|c|c|}
\hline & \multicolumn{2}{|c|}{ Preferred behaviour } & \multicolumn{2}{|c|}{ Perceived behaviour } & \multirow{2}{*}{$Z$} & \multirow{2}{*}{$p$} \\
\hline & $M$ & $S D$ & $M$ & $S D$ & & \\
\hline \multicolumn{7}{|l|}{ Volleyball $(n=71)$} \\
\hline Training and instruction & 4.37 & 0.41 & 3.52 & 0.90 & -6.11 & $<0.001$ \\
\hline Positive feedback & 4.02 & 0.67 & 3.33 & 0.77 & -5.22 & $<0.001$ \\
\hline Democratic behaviour & 3.13 & 0.70 & 2.60 & 0.87 & -4.31 & $<0.001$ \\
\hline Autocratic behaviour & 2.37 & 0.58 & 2.82 & 0.69 & -3.74 & $<0.001$ \\
\hline Social support & 3.09 & 0.61 & 2.86 & 0.64 & -2.92 & 0.004 \\
\hline \multicolumn{7}{|l|}{ Basketball $(n=21)$} \\
\hline Training and instruction & 4.04 & 0.54 & 3.45 & 0.57 & -3.57 & $<0.001$ \\
\hline Positive feedback & 3.69 & 0.54 & 3.42 & 0.47 & -2.08 & 0.037 \\
\hline Democratic behaviour & 3.09 & 0.62 & 2.79 & 0.69 & -1.72 & 0.085 \\
\hline Autocratic behaviour & 2.33 & 0.51 & 2.68 & 0.40 & -2.30 & 0.021 \\
\hline Social support & 2.91 & 0.42 & 2.66 & 0.70 & -1.62 & 0.106 \\
\hline
\end{tabular}

$p$ values for two-tailed test

regarding coaching behaviours differed depending on the played sport, the perceived coach's behaviour still differed from the preferred coaching behaviours. The studied female basketball players only received from their coaches the expected amount of social support and democratic behaviours. In the case of women playing volleyball, the perceived coach's behaviour differed significantly (large or average effect sizes) from the preferred coaching behaviour in all the analysed aspects.

\section{Discussion}

According to the Multidimensional Model of Sport Leadership [20], the preferences of the athletes concerning the coach's behaviour and leadership styles differ depending on individual characteristics of the athletes and situational characteristics. The aim of this study was to verify whether sex belongs to the personal characteristics that are significantly related to the athletes' preferences concerning the coach's behaviour towards them. Previous studies conducted by foreign researchers [e.g. 12, 14, 15, 21] indicate that sex significantly differentiates the athletes in the scope of their expectations from the coach. Because of that, a verification whether the connection between sex and athletes' preferences would be present also in case of Polish athletes seemed very interesting.

The obtained results reveal that men prefer a more autocratic leadership style of the coach than women. This confirms the conclusions of earlier research on the significance of sex in leadership [10, 12, 13, 15].
Women, in turn, prefer a more participatory leadership style of coaches. They would like to have a greater sense of influence and more opportunities to make sports decisions. This complies with the previous results [e.g. 12, 16]. Females also prefer to receive from their coach more feedback, as well as more technical instructions than males [e.g. 10, 15].

No differences between women and men were observed in the social support dimension. The previous studies on American athletes demonstrated that men expected from their coaches a greater involvement in their personal lives and more help in fulfilling their own personal needs [10, 12]. Such differences were not observed among Australian athletes, which suggests that cultural differences may also play a role when it comes to the athlete's expectations of their coach in this dimension [16].

However, the observed differences in women's and men's preferences are slight, which is confirmed by the calculated effect sizes. Both men and women expect from their coaches mostly detailed information necessary to master the technique and tactics in a specific sport. Thus, it is crucial to the athletes for the coach to pay attention to the improvement of the quality of the movements performed by them and to structure and coordinate their actions. Relatively often, they also expect from their coaches positive feedback regarding the quality of the performed tasks. Contrary to previous studies [e.g. 12], the results of this research indicate that Polish athletes have a comparatively small need for receiving social support from their coach. The lack of preference for such type of coaching behaviour may 
indicate that Polish athletes, similarly to the Australian ones [16], do not rely on their coaches when it comes to obtaining support and fulfilling their personal needs. These results denote, therefore, that male and female athletes have similar coaching behaviour preferences and they may be more similar than previously assumed.

The consideration of the trained sport as a variable differentiating athletes' preferences in the analyses allowed to obtain interesting results. The data suggest that the trained sport differentiates the athletes' preferences only among women. As compared with basketball players, volleyball players expected from their coaches more training-related instructions, more positive feedback, more democratic behaviours, and more social support. The obtained differences were greater than those between men and women in general. According to Koivula [22], stereotypically male sports are the ones requiring strength, speed, risk, and a team spirit, as well as the ones in which physical contact in unavoidable. Female sports are mainly 'non-contact' ones, in which efficient cognitive processes, advanced skills, and, above all, aesthetics play a major role [23]. Moreover, Wrisberg et al. [24] suggested that male- or androgynous-type women would be especially interested in team sports, dominated by typically male behaviours such as aggression, assertiveness, and direct contact with the opponents. On the basis of such classifications, it can be stated that basketball is a sport that will be more frequently chosen by women who are intensely masculine and that this might be the reason for the similar preferences of women playing basketball and men.

Men and women have slightly different expectations from the coach. The coaches themselves, however, do not fully adjust their behaviour to the sex of the athletes they work with. The research shows that the coaches of female teams exhibited only more supportive behaviours than the coaches of male teams. In the remaining leadership dimensions, they did not differ (according to the athletes). Moreover, in the female group, the coach's behaviours did not differ significantly depending on the played sport. The studied female volleyball and basketball players perceived the behaviour of their coaches in a very similar way. This may be caused by the fact that in all the teams the coach was male. In sports, there are over 10 times fewer female coaches than male ones. In team sports on a professional level, this difference is even greater. The obtained results suggest that male coaches are not fully aware of the differences or are not willing to change their behaviour when they start working with women. Interestingly, significant differences between the perceptions of the coach's behaviours were found in the male group depending on the played sport. This study did not control for the league in which the studied team was competing, which might have considerably influenced the results. Thus, it would be worthwhile to schedule another study that would take this factor into account as well.

Additionally, the analysis of the results demonstrated that athletes had higher expectations of the coach as compared with his or her actual behaviour. The athletes received from their coaches fewer training-related instructions, less positive feedback, fewer democratic behaviours, less social support, and more autocratic behaviours than they would have expected. This was true both for women and men. Especially big differences were noted in the training and instruction and positive feedback dimensions, both among female and male athletes playing volleyball and basketball. The obtained data indicate that Polish athletes may think that the coaches supply them with appropriate technical and tactical instructions and provide suitable information concerning the quality of the performance of the respective tasks in an inadequate manner. Thus, a practical suggestion for the coaches ensues to pay attention to their charges' correctness of task performance, express their approval, and provide detailed instructions relating to the given task more frequently because it is highly probable that the athletes - both female and male, playing different sports expect these behaviours from them. What is also essential, this type of communications from the coaches has a significant impact on the improvement of the athletes' performance [e.g. 25, 26]. The obtained data suggest, in accordance with the Multidimensional Model of Sport Leadership [20], that coaches adjust their behaviour depending on the athletes' preferences and situational requirements to a much smaller extent than they should.

\section{Conclusions}

The obtained results indicate that women and men differ in their preferences concerning coaching behaviours. These differences, however, are not big. Moreover, the played sport may have a significant influence on the expectations regarding the coach's behaviour; this observation is, however, limited to women. Among men, the played sport did not significantly differentiate the athletes in their coaching behaviour preferences. Regardless of the athletes' sex, coaches provided them with less behaviours than the athletes would have expected. This implies that coaches adjust their behaviour 
to the athletes' preferences and the situational requirements in an inadequate manner.

\section{Disclosure statement}

The author does not have any financial interest and did not receive any financial benefit from this research.

\section{Conflict of interest}

The author states no conflict of interest.

\section{References}

1. Martens R. Coaches guide to sport psychology. Champaign: Human Kinetics; 1987.

2. Horn TS. Leadership effectiveness in sport domain. In: Horn TS (ed.), Advances in sport psychology. Champaign: Human Kinetics; 1992; 181-1999.

3. Chelladurai P, Saleh SD. Dimensions of leader behavior in sports: development of a leadership scale. J Sport Psychol. 1980;2:34-45; doi: 10.1123/jsp.2.1.34.

4. Chelladurai P. Leadership in sports organizations. Can J Appl Sport Sci. 1980;5(4):226-231.

5. Smoll FL, Smith RE. Leadership behaviors in sport: a theoretical model and research paradigm. J Appl Soc Psychol. 1989;19(18):1522-1551; doi: 10.1111/j.15591816.1989.tb01462.x.

6. Carron AV, Hausenblas HA, Eys MA. Group dynamics in sport, $3^{\text {rd }}$ ed. Morgantown: Fitness Information Technology; 2005.

7. Riemer HA. Multidimensional model of coach leadership. In: Jowett S, Lavallee D (eds.), Social psychology in sport. Champaign: Human Kinetics; 2007; 57-73.

8. Chelladurai P, Carron AV. Leadership. CAHPER Sociology of Sport Monograph Series. Calgary: University of Calgary; 1978.

9. Chelladurai P. Leadership in sports. In: Tenenbaum G, Eklund RC (eds.), Handbook of sport psychology, $3^{\text {rd }}$ ed. Hoboken: John Wiley \& Sons, Inc.; 2007; 113-135.

10. Beam JW, Serwatka TS, Wilson WJ. Preferred leadership of NCAA division I and II intercollegiate student-athletes. J Sport Behav. 2004;27(1):3-17.

11. Chelladurai P, Arnott M. Decision styles in coaching: preferences of basketball players. Res Q Exerc Sport. 1985;56(1):15-24; doi: 10.1080/02701367.1985.1060 8426 .

12. Chelladurai P, Saleh SD. Preferred leadership in sports. Can J Appl Sport Sci. 1978;3:85-92.

13. Terry PC. The coaching preferences of elite athletes competing at Universiade '83. Can J Appl Sport Sci. 1984; 9(4):201-208.

14. Terry PC, Howe BL. Coaching preferences of athletes. Can J Appl Sport Sci. 1984;9(4):188-193.

15. Riemer HA, Toon K. Leadership and satisfaction in tennis: examination of congruence, gender and ability. Res Q Exerc Sport. 2001;72(3):243-256; doi: 10.1080/ 02701367.2001 .10608957$.
16. Sherman CA, Fuller R, Speed HD. Gender comparisons of preferred coaching behaviors in Australian sports. J Sport Behav. 2000;23(4):389-406.

17. Chelladurai P, Haggerty TR. A normative model of decision styles in coaching. Athl Admin. 1978;13:6-9.

18. Wałach-Biśta Z. A Polish adaptation of Leadership Scale for Sports - a questionnaire examining coaching behavior. Hum Mov. 2013;14(3):265-274; doi: 10.2478/ humo-2013-0032.

19. King BM, Minium EW. Statistics for psychologists and educators [in Polish]. Warszawa: PWN; 2009.

20. Chelladurai P. Leadership in sports: a review. Int J Sport Psychol. 1990;21(4):328-354.

21. Chelladurai P. Discrepancy between preferences and perceptions of leadership behavior and satisfaction of athletes in varying sports. J Sport Psychol. 1984;6(1): 27-41.

22. Koivula N. Perceived characteristics of sports categorized as gender-neutral, feminine and masculine. J Sport Behav. 2001;24(4):377-393.

23. Colley A, Roberts N, Chipps A. Sex-role identity, personality and participation in team and individual sports by males and females. Int J Sport Psychol. 1985;16(2): 103-112.

24. Wrisberg CA, Draper MV, Everett JJ. Sex role orientations of male and female collegiate athletes from selected individual and team sports. Sex Roles. 1988;19(1-2): 81-90; doi: 10.1007/BF00292466.

25. Landin D. The role of verbal cues in skill learning. Quest. 1994;46(3):299-313; doi: 10.1080/00336297. 1994.10484128.

26. Zatoń K, Cześniewicz I, Szczepan S. The effect of verbal feedback on biomechanical performance during swimming ergometry. Hum Mov. 2018;19(1):3-9; doi: 10.5114/hm.2018.73606. 